\title{
Studying the Fatigue Life of a Non-pneumatic Wheel by Using Finite-Life Design for Life Prediction
}

\author{
Zhen Xiao - You Qun Zhao* - Fen Lin - Ming Min Zhu - Yao Ji Deng \\ Nanjing University of Aeronautics and Astronautics, College of Energy and Power Engineering, \\ Department of Automotive Engineering, China
}

\begin{abstract}
To avoid pneumatic tire puncture, blow-out and other problems, a new type of non-pneumatic safety wheel called the mechanical elastic wheel (ME-Wheel) has been developed and investigated. The durability of the ME-Wheel is studied to improve its life; at the same time, the best preventive maintenance period can also be provided for the users, to ensure the safety and reliability of the ME-Wheel in operating conditions. The finite-life design method is proposed to predict the ME-Wheel life; the weakest component of ME-Wheel is ascertained by analysing its structure static strength, and the predicted model of pin for lifetime theory is established by using finite-life design method. Furthermore, the ME-Wheel durability is simulated using the finite element method (FEM) on the basis of the established virtual proving ground, and the enhancement coefficient is combined to calculate ME-Wheel lifespan. Finally, the results of theoretical calculation and simulation are verified using endurable road testing. The results show that the methods of theoretical calculation and simulation, which are applied in our paper to predict the lifespan of ME-Wheel, are highly congruent with the experimental results. Therefore, the proposed method is also entirely suitable for other mechanical structures in the durability research field.
\end{abstract}

Keywords: non-pneumatic wheel, durability, finite-life design, finite element analysis, life test

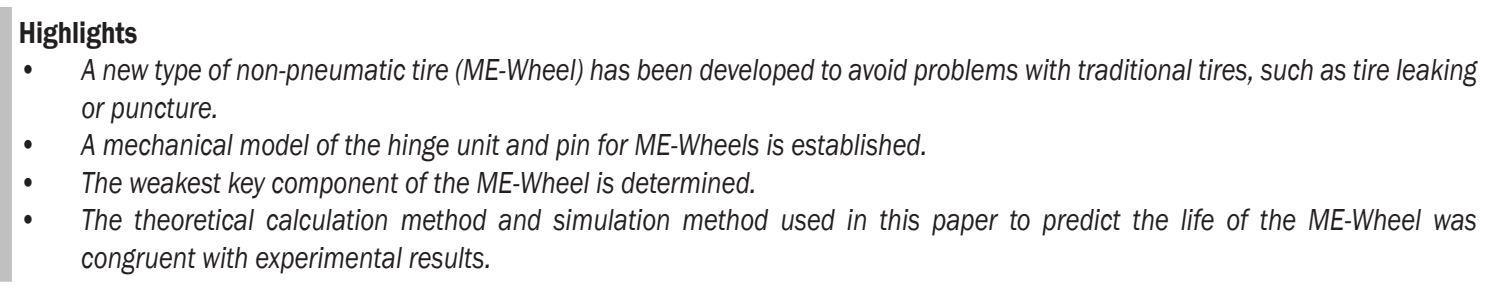

\section{INTRODUCTION}

Wheels are one of the most essential parts of a vehicle; in particular, military vehicles need wheels with excellent rupture-proof ability in different extreme environments. Many tire companies and research institutes have studied non-pneumatic safety wheels [1] to [4] to protect the safety of passengers. Durability is one of the key performance indicators of the ME-Wheel; its lifespan has an important influence on economy and safety [5] and [6]. The concept of finite-life design requires that no fatigue damage occur during products life-cycle [7]. The finite-life design method is used to study lifetime and obtain the rated lifespan of ME-Wheels; vehicle wheels are not to be damaged, and passengers are to be protected throughout the lifecycle.

An analytical model of a non-pneumatic tire has been proposed by Gasmi et al. [8] and Gasmi and Joseph [9], which consists of a flexible ring belt and a spoke. The main parameters were analysed and verified by finite element method, and researchers studied the outflow field of non-pneumatic tires with contact surfaces and radial stiffness [10] to [12]. Wang et al. [13] and [14] presented a reduced- order compensation scheme for computing the static deformation response of a thick ring supported by a unilateral elastic foundation to an arbitrarily applied force. This scheme avoided solving a set of complex non-linear differential equations and gave an efficient tool for analysing and designing such systems. To satisfy the needs of the development of a modern national defence industry, this paper researched a new type of non-pneumatic wheel: the mechanical elastic wheel (ME-Wheel) [15]. The main components are flexible tire body, hinge unit and suspension hub. To improve the adaptability of military vehicles in complex environments, the ME-Wheel is designed with a statically indeterminate structure. Compared with the conventional pneumatic tire, it has no potential risk factors such as flat tire or leakage. Moreover, it provides excellent comfort with its double-buffered damping structure. Wang et al. [16] have studied the ME-Wheel's structure and ride comfort. Wang et al. [17] have analysed the relationship among the excitation frequency, radial deformation, the bending stiffness of combined elastic rings, and the laminated structure parameters of built-up elastic rings. Zang et al. [18] and [19] have analysed the radial stiffness and the influencing factors of the ME-Wheel. Li et al. [20] 
have studied the mechanical properties of ME-Wheels and obtained the relationship between the tangential deformation and bending angle of the combined elastic rings via the Laplace transform. Du et al. [21] and [22] established a non-linear three-dimensional finite element model of the wheel interacting with soil, and simulated the different rotational speeds.

Although many researchers have made in-depth studies of life estimation on other pneumatic tire and mechanical products [23], none have studied the MEWheel durability. Sokolov [24] and [25] predicted the fatigue life of the pneumatic tires by using the finite element FEM and developed the experimental fatigue curves for rubber-cord composites. In addition, a tensile test of the rubber cord was carried out, and the fatigue curve of the tire under stress and strain conditions was constructed. Topac et al. [26] studied the causes of the fatigue failure of commercial vehicle wheels near ventilation holes. The finite element model was established using ANSYS / Workbench, and the static stress was analysed. Then the wheel was predicted by S-N curve, based on the stress life method and finally, the wheel structure was improved. Rosa et al. [27] evaluated the damage of mechanical components with a stress-controlled rheological spring-slider model combined with finite element method. Ettefagh et al. [28] carried out fatigue life influenced by vibration performance of a friction stir-spot-welded specimen, verified by the finite method and related experiments during analysing four different welded methods. Dobado and Morales [29] studied the fatigue failure of the 7075-T6 aluminium alloy cantilever by using the multi-axis strain energy density and evaluated the potential application of light alloy mechanical parts in the automotive industry.

The ME-Wheel is subjected to complex alternating load during movement; therefore, it is very difficult to predict its lifetime. The prediction method proposed in this paper is to obtain the weakest part of the structure by static strength analysis and calculate the lifetime of the part; the rapid prediction of MEWheel life is then realized. The research method used in this paper is that the ME-Wheel finite element model is established, and its validity is verified using a static strength test. After that, the weakest part of ME-Wheel is obtained by finite element simulation. Moreover, the wheel lifetime prediction model is calculated by using the finite-life design method, and the analytical results of lifetime prediction are obtained. Finally, the virtual proving ground is established by the finite element method, and the durability of the ME-Wheel is simulated and compared with the endurance road testing results.

\section{STRUCTURE AND STATIC STRENGTH ANALYSIS OF ME-WHEEL}

The whole lifetime of the structure depends on the lifetime of parts in mechanical structures [30], and the life prediction of ME-Wheel can be achieved by calculating the life of the weakest parts.

\subsection{ME-Wheel Structure}

Fig. 1 shows the structure of ME-Wheel, which is composed of the flexible tire body, hinge unit, pin, clamping ring, combined elastic rings, and suspension hub components. The assembly relationship is as follows:

1) The five combined elastic rings locked by twelve sets of clamping rings are juxtaposed to form the ME-Wheel frame, as shown in Fig. 2.

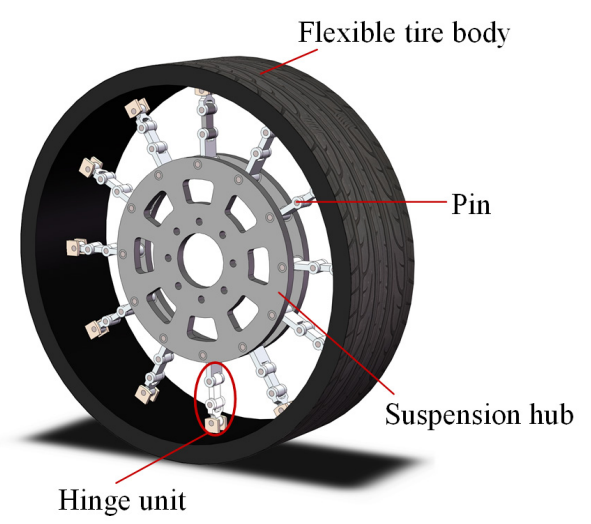

Fig. 1. ME-Wheel configuration

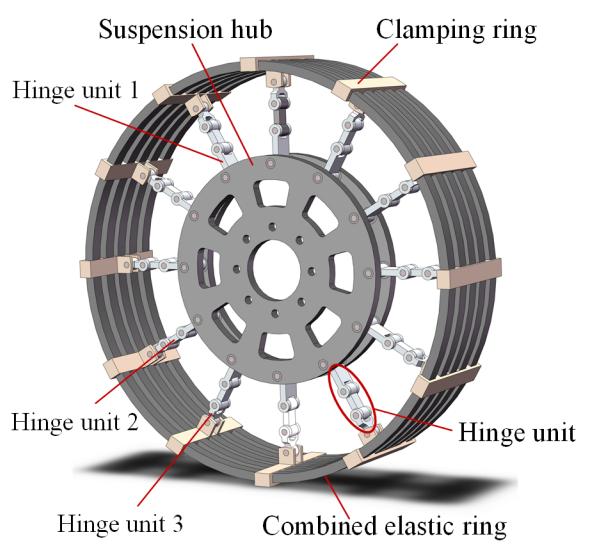

Fig. 2. ME-Wheel frame

2) The suspension hub is installed at the centre of the combined elastic rings, and the clamping ring and the suspension hub are connected by the hinge unit. 
3) The combined elastic rings are embedded in the flexible tire body.

\subsection{Static Strength Analysis of ME-Wheel}

The static strength of the ME-Wheel 3D finite element model is calculated using COSMOS/WORKS finite element simulation software according to the bench test condition. The various components grid density of ME-Wheel was different to save computing resources as much as possible without affecting the simulation results. The finite element method (FEM) size is pin $6 \mathrm{~mm}$, hinge group $8 \mathrm{~mm}$, clamping ring $8 \mathrm{~mm}$, combined elastic rings $10 \mathrm{~mm}$, suspension hub $10 \mathrm{~mm}$, flexible tire body $16 \mathrm{~mm}$, pavement 200 $\mathrm{mm}$. The number of nodes is 290,033 , the number of mesh elements is 160,764 , and the element types are tetrahedral mesh. The road model is applied a fixed constraint, and the centre of suspension hub is applied a vertical load to calculate the radial stiffness; the load settings are $5 \mathrm{kN}, 10 \mathrm{kN}, 15 \mathrm{kN}, 20 \mathrm{kN}, 25 \mathrm{kN}, 30 \mathrm{kN}$, $35 \mathrm{kN}$. As shown in Fig. 3. The radial stiffness of the wheel is tested using the ME-Wheel radial mechanical test bench; the test bench is shown in Fig. 4. Fig. 5 is the contrast curves of radial stiffness between MEWheel simulation values and experimental values.

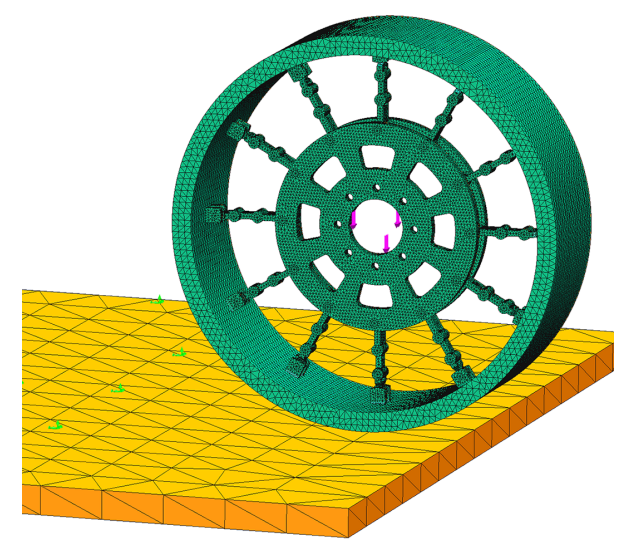

Fig. 3. Define constraints and loads

As seen in Fig. 5, the radial stiffness curve simulation values of ME-Wheel agree with the experimental data, and the correctness of the finite element model is verified. It shows that the finite element model of the ME-Wheel is satisfactory with the required simulation.

The static strength of the ME-Wheel is simulated, and the stress nephogram is shown in Fig. 6.

Seen from Fig. 6, when the ME-Wheel is applied to the radial load, the pin is subjected to the maximum stress, so the pin is the weakest component, and the lifetime of the ME-Wheel depends on the durability of the pin.

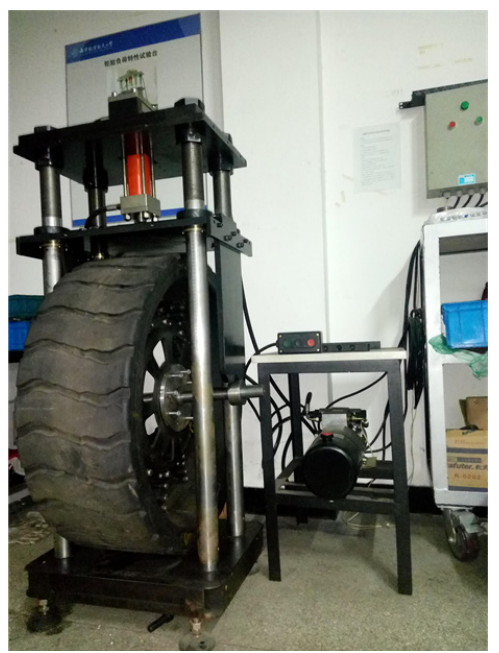

Fig. 4. ME-Wheel bench test

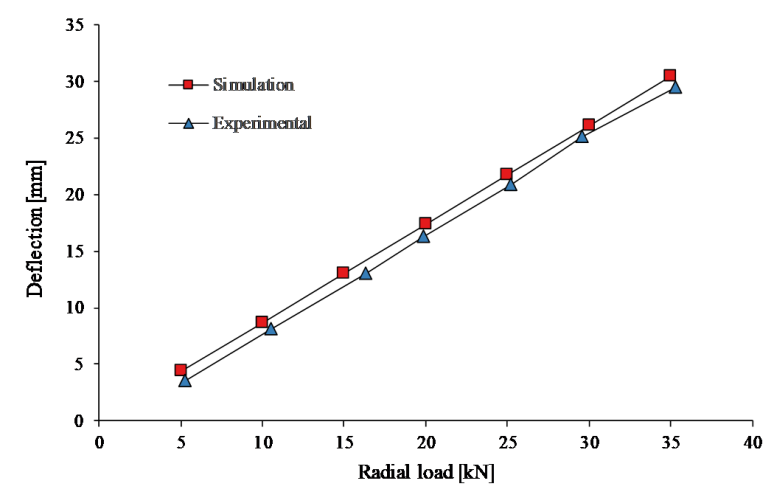

Fig. 5. Radial stiffness comparison curves of ME-Wheel

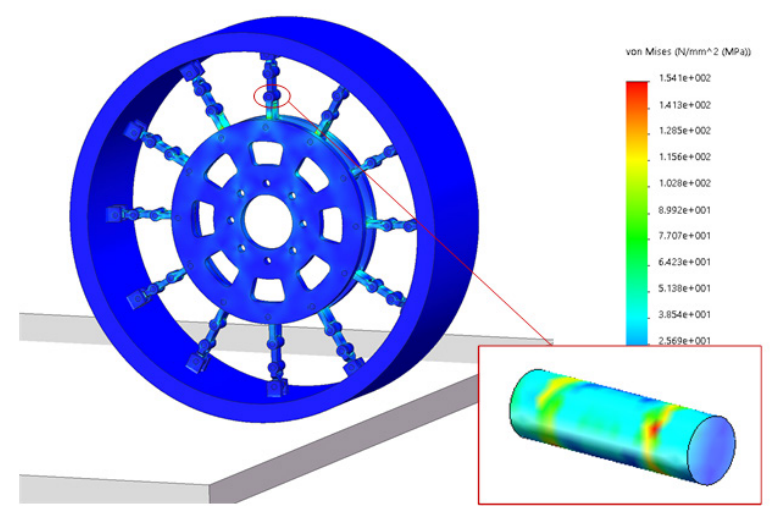

Fig. 6. ME-Wheel radial loading stress nephogram

Because the pin plays a crucial role in the MEWheel lifespan, a set of hinge units is extracted to perform uniaxial tensile tests to verify the 
effectiveness of the pin-hinge unit model. Moreover, to ensure the validity of uniaxial tensile test, the experimental fixture is completely designed according to the internal condition of the hinge unit assembly. The tensile test is shown in Fig. 7. The contrast curves of tensile test results and simulation results are shown in Fig. 8.

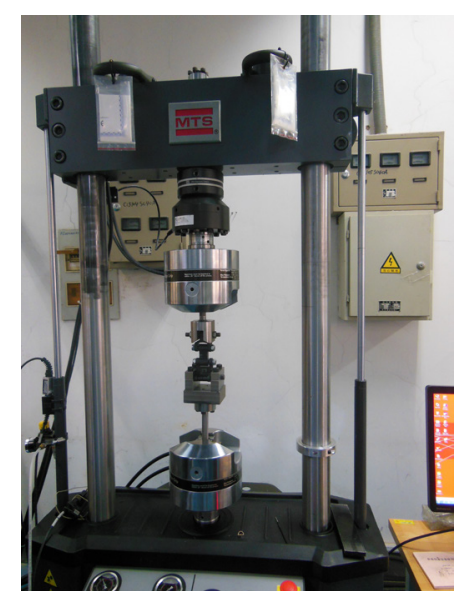

Fig. 7. Hinge unit tensile test

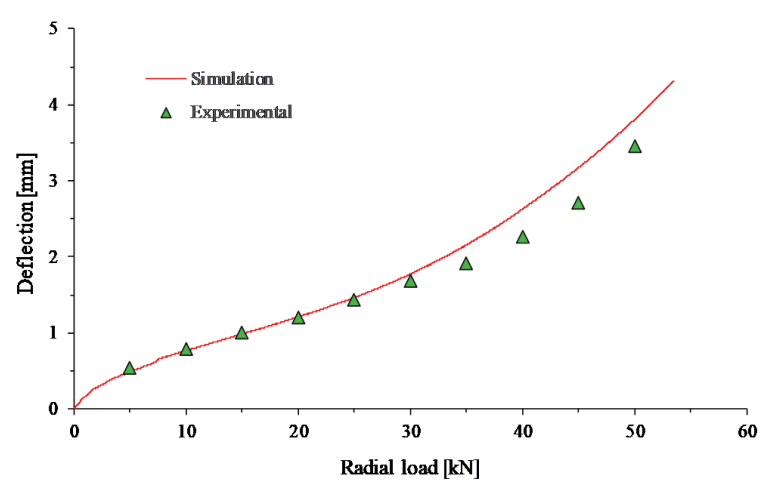

Fig. 8. Comparison of experiments and simulation results

Through the tensile test and finite element simulation, it can be seen that the deformation of the hinge unit is caused by the bending deformation of the pin. As can be seen from Fig. 8, the finite element simulation is a relatively good match with the hinge unit tensile test curve, for which the maximum relative error is $14.4 \%$, and the average error is $4.9 \%$. Thus, the finite element model validity of the pin-hinge unit assembly is verified, and the requirements of later research are met.

\section{LIFE PREDICTION OF PIN UNDER FINITE-LIFE DESIGN}

The mechanical structure of the anti-fatigue design (fatigue life design) is divided into finite-life design and infinite-life design. Infinite-life design is suitable for fixed mechanical structures, while the finite-life design is applied to a movable mechanical structure, and the finite-life design is much closer to the real environment. The basic flow chart of finite-life design is shown in Fig. 9.

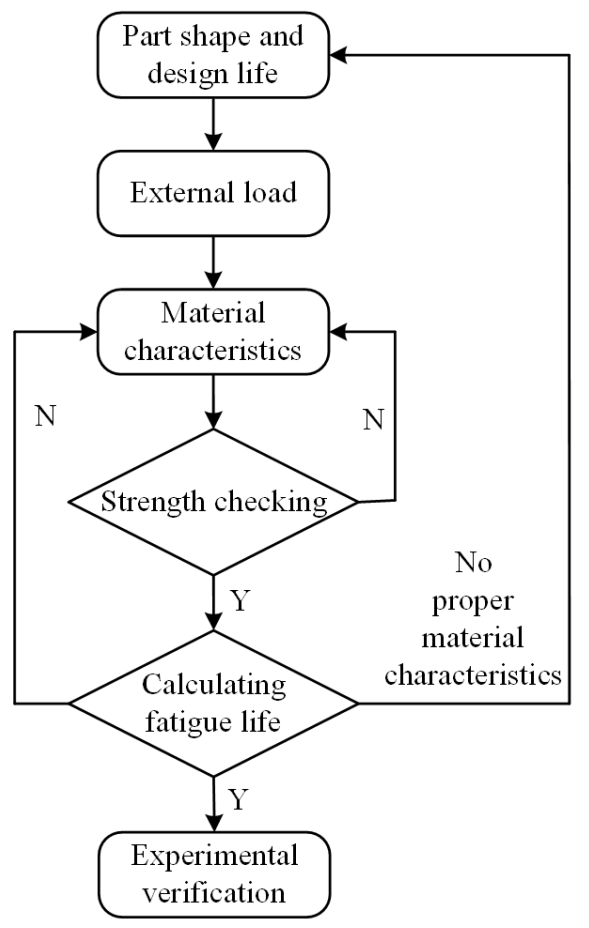

Fig. 9. Finite-life design flow

\subsection{Mechanical Analysis of ME-Wheel}

The stress of the hinge unit at different positions is analysed when the ME-Wheel is stationary; the hinge unit 1 to 12 is clockwise from the top hinge unit, as shown in Fig. 10a. From the ME-Wheel's bearing way, the suspension hub is in the suspended state when the ME-Wheel is subjected to loads from suspension hub. The upper half of the hinge units 1,2 , $3,11,12$ is in the stretched state, Hinge units 5, 6, 7, 8, 9 in the lower part are under compression and bending deformation around the hinge point; at this time, the hinge unit does not bear any force. Hinge unit 4 and 10 are in a level-free condition, and the bearing force of hinge units is shown in Fig. 10b.

If the bearing force of the ME-Wheel in the initial position is FZ, the forces of hinge Units 1, 2, 3, 11, 12 are F1, F22, F32, F31, F21. The force balance equation of the ME-Wheel can be expressed as: 
a)

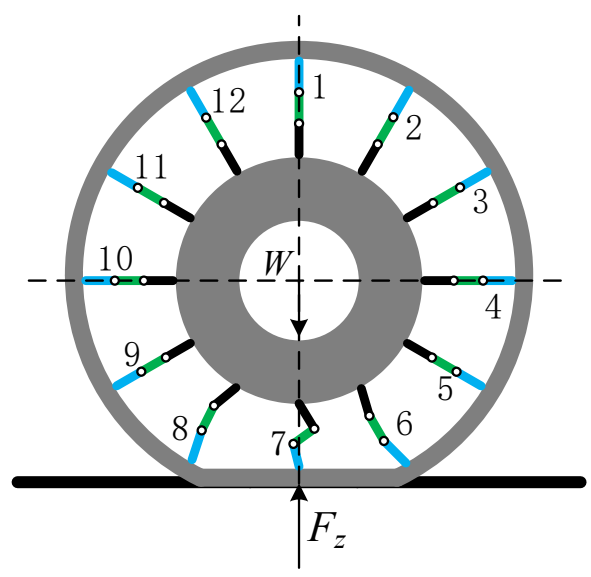

b)

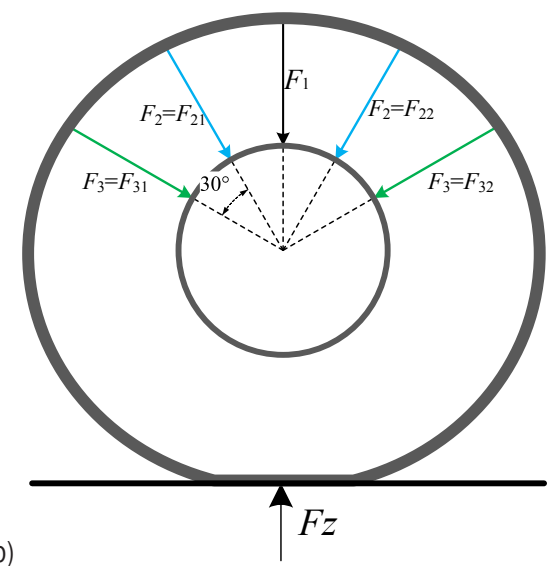

Fig. 10. The characterization of hinge unit for ME-Wheel; a) the number of hinge unit, and b) the load conditions of hinge unit

$$
\left\{\begin{aligned}
F_{21} & =F_{22} \\
F_{31} & =F_{32} \\
F_{Z} & =F_{1}+2 F_{21} \cos \frac{\pi}{6}+2 F_{31} \cos \frac{\pi}{3} \\
& =F_{1}+2 F_{22} \cos \frac{\pi}{6}+2 F_{32} \cos \frac{\pi}{3}
\end{aligned}\right.
$$

For convenience, $F_{21}$ and $F_{22}$ are marked as $F_{2}$, $F_{31}$ and $F_{32}$ are marked as $F_{3}$. Therefore, the above equation becomes

$$
\left\{\begin{array}{l}
F_{2}=F_{21}=F_{22} \\
F_{3}=F_{31}=F_{32} \\
F_{Z}=F_{1}+2 F_{2} \cos \frac{\pi}{6}+2 F_{3} \cos \frac{\pi}{3}
\end{array} .\right.
$$

If the deformation amount of hinge Unit 1 is $\Delta l_{1}$, hinge Unit 2 and 12 is $\Delta l_{2}$, and the hinge Unit 3 and 11 is $\Delta l_{3}$, all hinge unit tensile stiffness is $E A_{J}$, and the original length is $l$, the physical deformation equation is:

$$
\left\{\begin{array}{l}
\Delta l_{1}=\frac{F_{1} l}{E A_{J}} \\
\Delta l_{2}=\frac{F_{2} l}{E A_{J}} \\
\Delta l_{3}=\frac{F_{3} l}{E A_{J}}
\end{array}\right.
$$

According to the tensile deformation of hinge unit deformation, the compatibility equation of deformation is:

$$
\left\{\begin{array}{l}
\Delta l_{2}=\Delta l_{1} \cos \frac{\pi}{6} \\
\Delta l_{3}=\Delta l_{1} \cos \frac{\pi}{3}
\end{array}\right.
$$

The solution obtained by Eqs. (2), (3) and (4) is:

$$
\left\{\begin{array}{l}
F_{1}=\frac{1}{3} F_{Z} \\
F_{2}=\frac{\sqrt{3}}{6} F_{Z} . \\
F_{3}=\frac{1}{6} F_{Z}
\end{array}\right.
$$

Seen from the above analysis and calculation results, the closer a hinge unit is located to the middle of the vertical position, the greater the force.

The pin in the ME-Wheel connects the clamping ring, hinge unit, and the suspension hub to each other, and allows the hinge unit to freely rotate within a certain angle between the clamping ring and the suspension hub during the moving process. Furthermore, the pin can also transfer torque from the suspension hub centre to the ME-Wheel.

When the ME-Wheel runs straight, the pin mainly bears the bending moment and shear force. A simplified drawing of the pin under stress is shown in Fig. 11.

According to the actual force of the hinge unit, $q$ in Fig. 11 is uniform load, $q$ and $F_{S}$ are the tension from the suspension hub and the supporting force from the hinge unit. The pin length is expressed by $l$. Based on the mechanical model in the diagram, the mechanical equilibrium equation is as follows,

$$
\sum F=0, \quad \sum M=0,
$$


and calculates,

$$
\begin{gathered}
2 F_{S}=F, \quad M=\frac{q l^{2}}{8}, \\
\tau=\frac{F_{S}}{A},
\end{gathered}
$$

where $F_{S}$ is the support force from the hinge unit, $M$ is the bending moment on the pin, $\tau$ is the shear force on the pin, and $A$ is the cross-sectional area of the pin.

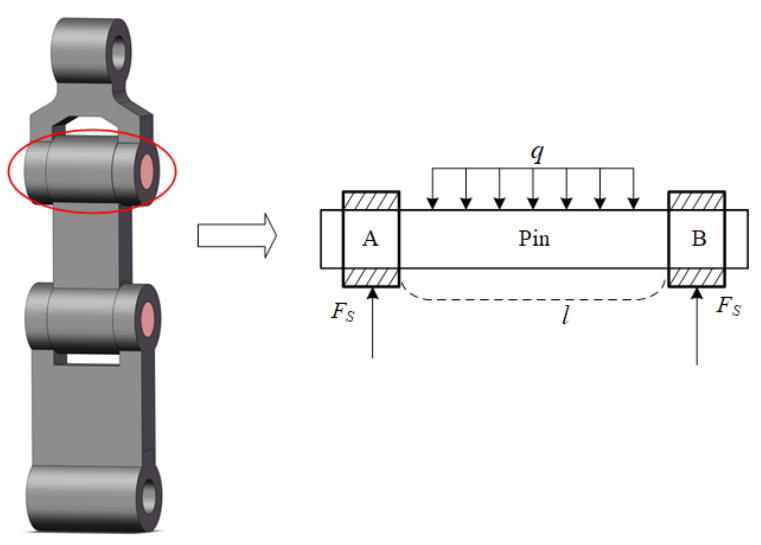

Fig. 11. Pin force diagram

When a vehicle moves, the tire is subjected to dynamic loads from the road. The formula is expressed as,

$$
F_{Z}=D F_{j Z}
$$

where $F_{j Z}$ is the vertical static load of the tire, and $D$ is the tire dynamic load coefficient.

According to the road testing, the average driving speed of the vehicle is $45 \mathrm{~km} / \mathrm{h}$, the road roughness coefficient $S_{0}=2 \times 10^{-6} \mathrm{~m}$, taking the dynamic load factor is 2.1 [31], calculates the dynamic load of the ME-Wheel as 36,015 N. The detailed calculation results are shown in Table 1.

Table 1. Calculation results of ME-Wheel mechanics

\begin{tabular}{cccc}
\hline Model & $F_{1}[\mathrm{~N}]$ & $\tau[\mathrm{MPa}]$ & $M[\mathrm{~N} \cdot \mathrm{mm}]$ \\
\hline Pin & 12005 & 53.1 & 25504 \\
\hline
\end{tabular}

When the ME-Wheel is cornering, the force of the vehicle is shown in Fig. 12.

It can be seen from Fig. 12, the establishment of the vehicle when turning the frame of reference, the wheel will be used by the inertia force at this time. If the vehicle is regarded as a rigid body, its inertial centrifugal force is,

$$
F_{x}=M R \omega^{2}=\frac{M V^{2}}{R}
$$

where $M$ is the vehicle mass, the $R$ is the turning radius, and $V$ is the instantaneous speed of the turning.

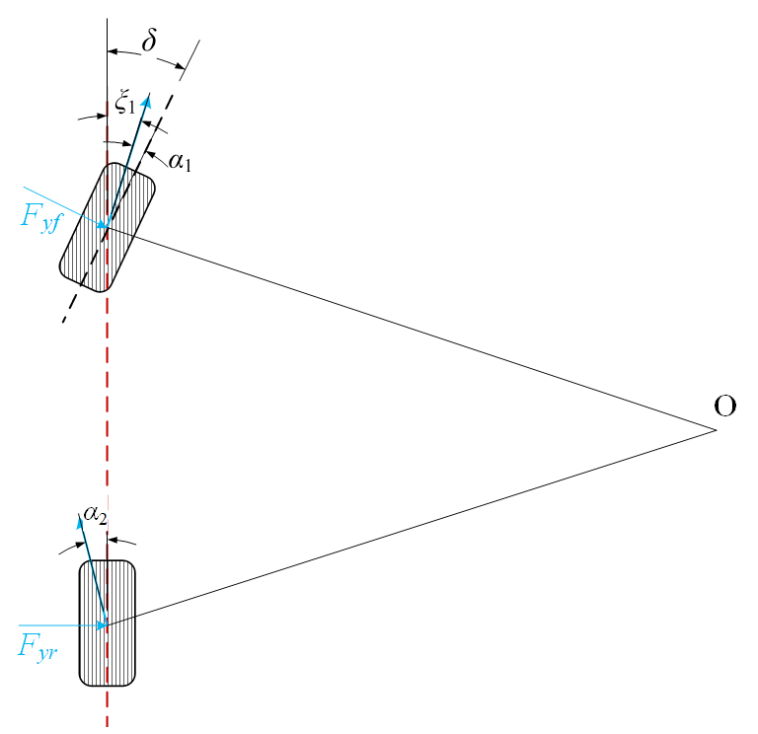

Fig. 12. Wheel steering force

When the vehicle turns, its lateral force is provided by friction, and its value cannot exceed the ground adhesion, that is:

$$
\left\{\begin{array}{l}
F_{y} \leq F_{\varphi} \\
F_{y \max }=F_{\varphi}=\varphi F_{N}
\end{array}\right.
$$

where $\varphi$ is the adhesion coefficient and $F_{N}$ is the dynamic load of the wheel. Vehicle steering is due to the lateral force of the tire. For all vehicles running at a speed of $V$, the sum of all lateral forces on the tire is equal to mass multiplied by the centripetal acceleration, that is,

$$
\sum F_{y}=F_{y f}+F_{y r}=\frac{M V^{2}}{R}
$$

Among them, $F_{y f}$ and $F_{y r}$ are the lateral forces acting on the front and rear axle of the ME-Wheel, respectively.

Table 2. The relationship between adhesion and lateral force

\begin{tabular}{cccc}
\hline $\begin{array}{c}\text { Speed } \\
{[\mathrm{km} / \mathrm{h}]}\end{array}$ & $\begin{array}{c}\text { Adhesion } \\
{[\mathrm{N}]}\end{array}$ & $\begin{array}{c}\text { ME-Wheel lateral force } \\
{[\mathrm{N}]}\end{array}$ & $\begin{array}{c}\text { Pin lateral force } \\
{[\mathrm{N}]}\end{array}$ \\
\hline 0 & 9800 & 0 & 0 \\
\hline 10 & 27440 & 2500 & 208.3 \\
\hline 20 & 29400 & 10000 & 833.3 \\
\hline 30 & 31360 & 22500 & 1875 \\
\hline 40 & 33320 & 33320 & 2776.7 \\
\hline
\end{tabular}

Because the ME-Wheel has 12 hinge units, the lateral force of each hinge (pin) unit is $F_{Y} / 12$. 
With each ME-Wheel bearing $1 \mathrm{t}$ load, the speed is $0 \mathrm{~km} / \mathrm{h}$ to $40 \mathrm{~km} / \mathrm{h}, \varphi=1$, its adhesion and lateral force are calculated, as shown in Table 2.

\subsection{Pin Life Prediction}

When the ME-Wheel moves, the loads of the hinge unit and pin are periodic loads. To study the mechanism of stress cycle and fatigue failure of the pin during wheel motion, the higher stress point of the pin is picked up and its stress is analysed. Fig. 13 shows the variation stress of a dangerous point with a loading angle.

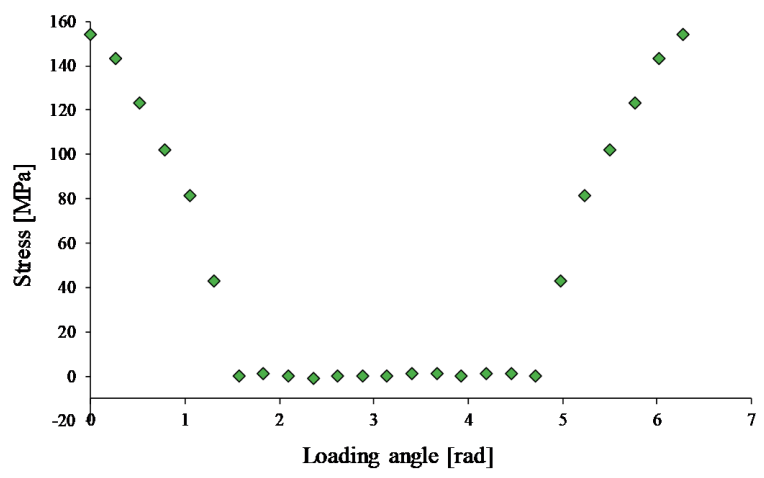

Fig. 13. The stress of the dangerous point with the loading angle

Seen from Fig. 13, the pin is subjected to symmetric cyclic stress. For the bending load applied symmetric cyclic stress, an improved Buch S-N curve is used [32]. Compared with the Buch idealization curve, the improved Buch curve is reflected in two aspects. First, the S-N curve of the part under the bending load should not be parallel to the S-N curve of the material. Second, the life N should be the turning point life $\mathrm{N} 0$ instead of constant 106. Its parts $\mathrm{S}-\mathrm{N}$ curve is calculated by the following formula, and the corrected part S-N curve is shown in Fig. 14.

$$
\lg N=\lg N_{0}-m_{2}\left(\lg \sigma-\lg \sigma_{-1 D}\right),
$$

where $M_{2}$ is the slope factor of the S-N curve, and the expression is as follows,

$$
m_{2}=\frac{\lg N_{0}-3}{\lg \left(\frac{0.9 \sigma_{b}}{\sigma_{-1 D}}\right)},
$$

where $\sigma_{-1}$ is the fatigue limit of material under symmetric cyclic stress; $\sigma_{-1 D}$ is the bending fatigue limit of the component, $N_{0}$ is the life at the turning point; $\sigma_{b}$ is the tensile strength of the material.

$$
\sigma_{-1 D}=\frac{\sigma_{-1}}{K_{\sigma D}}
$$

$$
K_{\sigma D}=\frac{K_{\sigma}+\frac{1}{\beta}-1}{\varepsilon},
$$

where $K_{\sigma}$ is the effective bending stress concentration factor, $\varepsilon$ is the size correction factor, and $\beta$ is the surface quality correction factor.

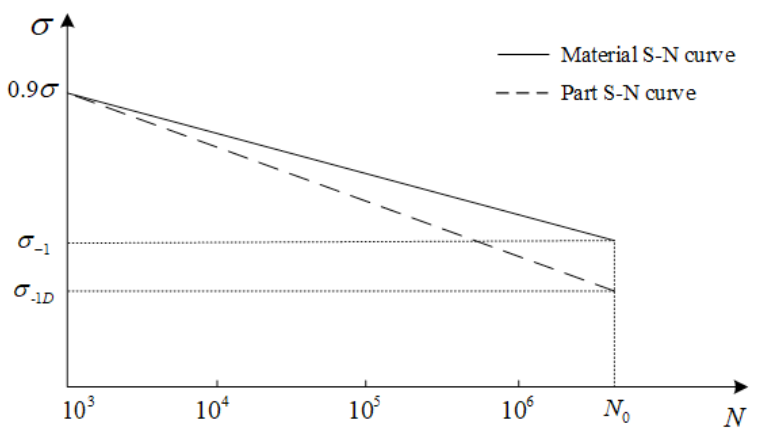

Fig. 14. Corrected part S-N curve

The work safety factor is calculated by Eq. (17):

$$
n_{\sigma}=\frac{\sigma_{-1 D N}}{\sigma_{\max }},
$$

where $\sigma_{-1 D N}$ is the fatigue life of the component when the design life is $N$. the design requires life of MEWheel is not less than $6000 \mathrm{~km}$.

$$
K_{\sigma}=\frac{\sigma_{-1}}{\left(\sigma_{-1}\right)_{k}} .
$$

The size correction factor $\varepsilon$ is obtained from the size coefficient curve, as shown in Fig. 15:

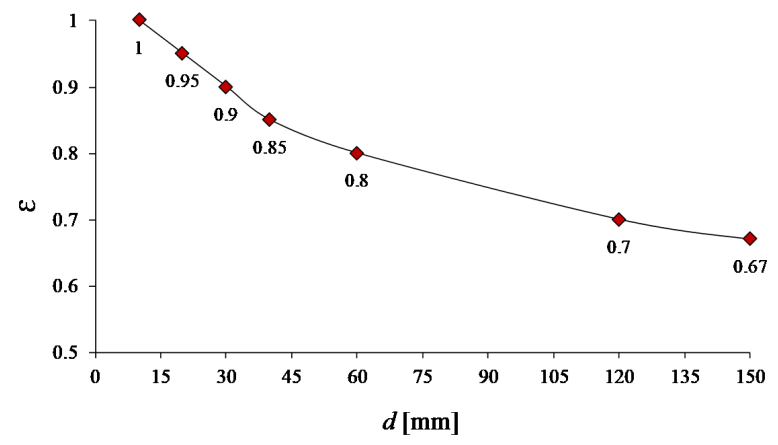

Fig. 15. Size coefficient curve

$$
\sigma_{s}=\frac{M}{W},
$$

where $W$ is the flexural factor of the section, the pin is cylindrical, and thus can be expressed by the following equation, 


$$
W=\frac{\pi d^{3}}{32}
$$

The material parameters of the ME-Wheel pin used in the formula are shown in Table 3.

Table 3. Pin material parameters

\begin{tabular}{lccccc}
\hline Model & \multicolumn{5}{c}{ Material Properties } \\
\hline \multirow{2}{*}{ Pin } & $\sigma_{-1}[\mathrm{MPa}]$ & $\sigma_{b}[\mathrm{MPa}]$ & $K_{\sigma}$ & $\beta$ & $N_{0}$ \\
\cline { 2 - 6 } & 380 & 710 & 1.8 & 0.92 & $3.4 \times 10^{6}$ \\
\hline
\end{tabular}

The dynamics analysis model and pin size parameters in Section 2.1 are taken in Eq. (19); it obtains $\sigma_{s}=150 \mathrm{MPa}$. and $n_{\sigma}=2.44$ is calculated by Eq. (17). According to the shape of the pin $[n]=2$, $n_{\sigma}>[n]$, it shows that components of the finite-life design are used safely in the design life of $N$.

The calculated stress of the component is,

$$
\sigma_{g}=[n] \sigma_{\max }
$$

where $\sigma_{g}=300 \mathrm{MPa}$ is calculated by Eq. (21). According to Fig. 14, the modified component S-N curve, the cycle number of the ME-Wheel can be calculated as $N=2.6 \times 10^{6}$ times, so the ME-Wheel life is $7300 \mathrm{~km}$. which is calculated by the finite-life design method.

The turning velocity of the testing vehicle is 20 $\mathrm{km} / \mathrm{h}$, according to Tables 1 and 2 , it can be obtained that the value of vertical load for the pin is 12,005 $\mathrm{N}$, however, the value of lateral force is $833.3 \mathrm{~N}$. Obviously, the lateral forces account for merely $6.94 \%$ of the vertical load. Moreover, theoretical calculations are based on the maximum vertical load value (the calculated value is conservative), but the calculated value of lifespan is not accurate enough because of coupling with the lateral force. Therefore, the influence of the lateral force should be neglected in the computing processes. However, to ensure the authenticity of simulation analysis, the composite conditions, including straight moving and steering motion, are comprehensively considered in the following finite element analysis.

\section{LIFE PREDICTION AND EXPERIMENTAL VERIFICATION OF THE ME-WHEEL}

\subsection{Three-Dimensional Model of a Virtual Proving Ground}

The durability test of a vehicle proving ground is the main way to test the fatigue durability of the vehicle. The test road in the vehicle durability proving ground includes high-speed runway (cement road), cobblestone pavement, washboards, Belgium block road and so on; each road makes the vehicle loads unique. Building a durability model of a virtual proving ground can give more realistic road load spectrum for ME-Wheel fatigue analysis.

The cobblestone pavement not only provides vertical loads for the ME-Wheel but also provides greater lateral and longitudinal impact loads; the washboard surface give periodic harmonic vibration and is often used to study the fatigue strength of the wheel under forced vibration; the Belgium block road is a random load road that is used to examine the structural strength and vibration characteristics of the ME-Wheel, and is one of the roads used in automotive durability testing. Therefore, a virtual proving ground model is built by the cobblestone pavement, washboards, Belgium block road and the cement road can better simulate the real running conditions of MEWheel. Not only is the computation time is saved, but also sufficient input load to the ME-Wheel is used to check the durability of the component. Moreover, the quick prediction of the ME-Wheel lifespan is realized.

According to the real proving ground situation, the specific parameters of durability road model are shown in Table 4. The cement road, Belgium block road, cobblestone pavement, washboards, curve, the length are $30 \mathrm{~m}, 15 \mathrm{~m}, 15 \mathrm{~m}, 15 \mathrm{~m}, 62 \mathrm{~m}$, respectively, and the width is $2 \mathrm{~m}$. The durability road model is shown in Fig. 16.

Table 4. The parameters of the durability road

\begin{tabular}{lcccc}
\hline Road & $\begin{array}{c}\text { Stone size } \\
{[\mathrm{mm}]}\end{array}$ & $\begin{array}{c}\text { Average } \\
\text { height [mm] }\end{array}$ & $\begin{array}{c}\text { Stone spacing } \\
{[\mathrm{mm}]}\end{array}$ & $\begin{array}{c}\text { Diameter } \\
{[\mathrm{m}]}\end{array}$ \\
\hline Washboards & 620 & 20 & 880 & -- \\
\hline $\begin{array}{l}\text { Belgium block } \\
\text { road }\end{array}$ & $200 \times 120$ & 5 & -- & -- \\
\hline $\begin{array}{l}\text { Cobblestone } \\
\text { pavement }\end{array}$ & 90 to 200 & 10 & -- & -- \\
\hline Curve & -- & -- & -- & 80 \\
\hline
\end{tabular}

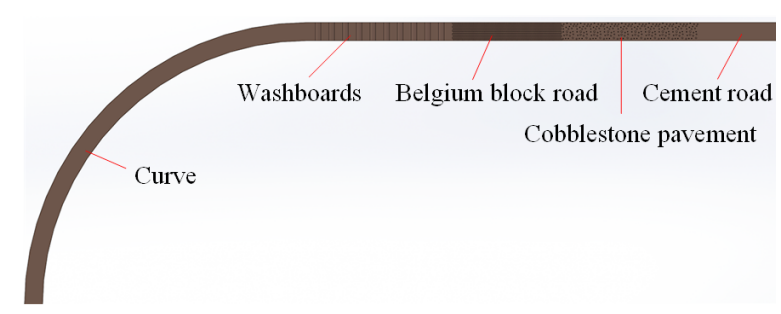

Fig. 16. The durability road model 


\subsection{ME-Wheel Durability Simulation}

According to the load to test the vehicle, the vertical load of $9800 \mathrm{~N}$ is applied in the centre of the suspension hub (the weight of the test vehicle is 4 tons, and each wheel bears a 1 ton load), the road is fixed, the contact between the road and the ME-Wheel is surface-to-surface contact; the gravity direction is defined as vertical downwards; a variable speed motor at the centre of the suspension hub is applied; the speed on the cement road is $60 \mathrm{~km} / \mathrm{h}$; on the cobblestone pavement, Belgium block road, washboards, the speed is $30 \mathrm{~km} / \mathrm{h}$, and $20 \mathrm{~km} / \mathrm{h}$ on the curve. The MEWheel motion simulation is shown in Fig. 17. The total running distance of the ME-Wheel is $137 \mathrm{~m}$, and the simulation time is $18.3 \mathrm{~s}$. Based on the motion simulation analysis, the dynamic load between the flexible tire body and the road surface is extracted by time as the abscissa, and the ME-Wheel load spectrum is established, as shown in Fig. 18. Seen from Fig. 18, the cobblestone pavement and washboard surfaces have a greater impact on ME-Wheel, so the enhancement coefficient of the two kinds of road is larger when the driving time is about $11 \mathrm{~s}$, a slight slip phenomenon occurs during the cornering of the ME-Wheel. The specific enhancement coefficients for different roads are shown in Table 5.

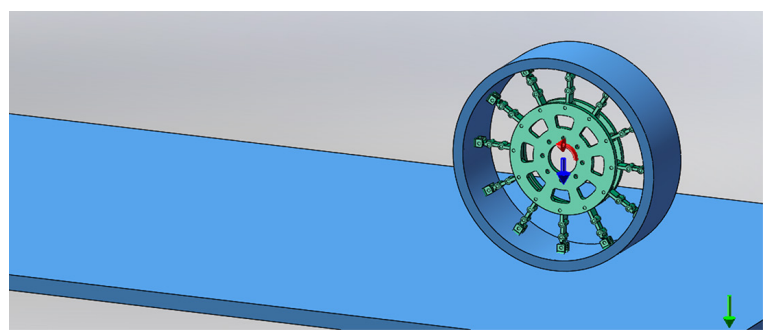

Fig. 17. ME-Wheel motion simulation

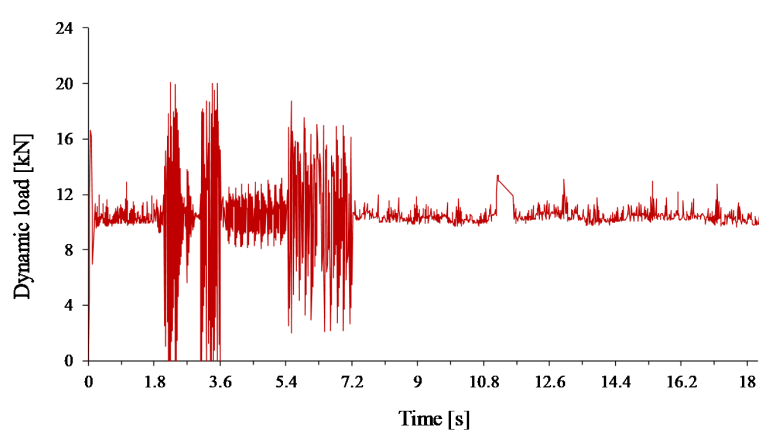

Fig. 18. ME-Wheel load spectrum

To make the collected load spectrum, information can be used for the analysis and calculation of fatigue performance; the rain-flow counting method is used for the cumulative frequency distribution statistics of the load history. The stress amplitude and mean values of each node are calculated by the rain flow counting tool and obtains amplitude-mean rain flow matrix, as shown in Fig. 19.

Table 5. Enhancement coefficient of different road

\begin{tabular}{|c|c|c|c|c|}
\hline Road & $\begin{array}{l}\text { Speed } \\
{[\mathrm{km} / \mathrm{h}]}\end{array}$ & $\begin{array}{c}\text { Enhancement } \\
\text { coefficient }\end{array}$ & $\begin{array}{c}\text { Proportion } \\
\text { of roads } \\
{[\%]}\end{array}$ & $\begin{array}{c}\text { Comprehensive } \\
\text { enhancement } \\
\text { coefficient }\end{array}$ \\
\hline Cement road & 60 & 0.8 & 21.90 & \multirow{5}{*}{5.22} \\
\hline $\begin{array}{l}\text { Cobblestone } \\
\text { pavement }\end{array}$ & 30 & 19 & 10.95 & \\
\hline $\begin{array}{l}\text { Belgium } \\
\text { block road }\end{array}$ & 30 & 4.4 & 10.95 & \\
\hline Washboards & 30 & 18.5 & 10.95 & \\
\hline Curve & 20 & 1.0 & 45.25 & \\
\hline
\end{tabular}

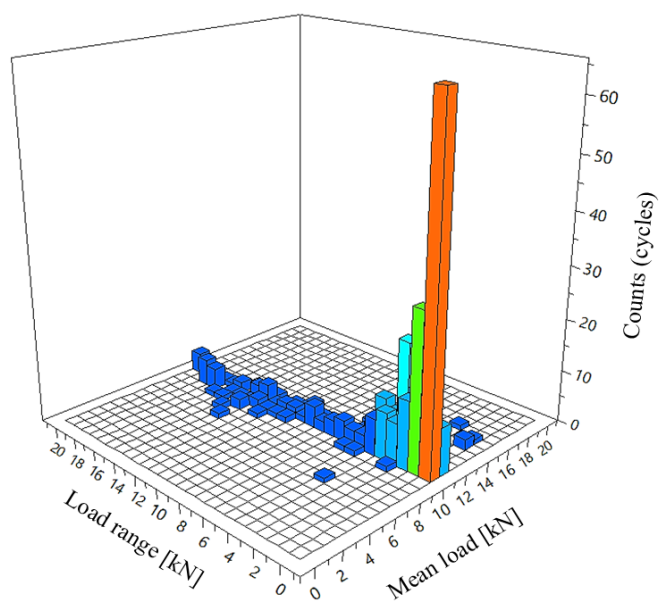

Fig. 19. Rain flow matrix

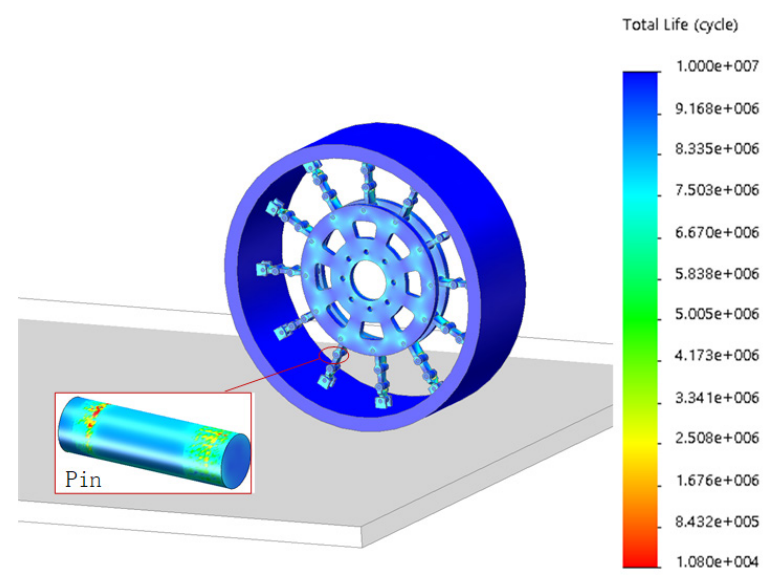

Fig. 20. ME-Wheel durability simulation results

The survival rate is set to $95 \%$ by using the nominal stress method and Goodman correction model 
in the simulation of the ME-Wheel. The durability of the ME-Wheel simulation results is shown in Fig. 20.

Seen from Fig. 20, the pin life is the lowest, and the minimum number of cycles on the endurance road is $1.08 \times 10^{4}$. Therefore, the overall life of the ME-Wheel structure obtained via dynamic finite element durability analysis is $\left(1.08 \times 10^{4}\right) \times 137 \times 5.22=7723.8 \mathrm{~km}$. In Section 2.2 , the theoretical calculation result is $7300 \mathrm{~km}$, and the error of simulation result is about $5.49 \%$. Thus, the finite element analysis of durability verifies the correctness of the finite-life design method used in this paper to calculate the pin life.

\subsection{Endurance Road Testing}

The test vehicle is a certain type of military vehicle that replaces all pneumatic tires with ME-Wheels and tests the ME-Wheel durability on endurance road. The vehicle odometer to record the driving distance is used. Specific data for endurance road testing are shown in Table 6. Fig. 21 is an endurance road testing image of ME-Wheel.

Table 6. ME-Wheel endurance road testing data

\begin{tabular}{|c|c|c|c|c|}
\hline Road & $\begin{array}{l}\text { Speed } \\
{[\mathrm{km} / \mathrm{h}]}\end{array}$ & $\begin{array}{c}\text { Enhancement } \\
\text { coefficient }\end{array}$ & $\begin{array}{c}\text { Proportion } \\
\text { of roads } \\
{[\%]}\end{array}$ & $\begin{array}{c}\text { Comprehensive } \\
\text { enhancement } \\
\text { coefficient }\end{array}$ \\
\hline Cement road & 60 & 0.8 & 30 & \multirow{7}{*}{7.32} \\
\hline $\begin{array}{l}\text { Cobblestone } \\
\text { pavement }\end{array}$ & 30 & 19 & 20 & \\
\hline $\begin{array}{l}\text { Belgium } \\
\text { block road }\end{array}$ & 30 & 4.4 & 20 & \\
\hline Washboards & 30 & 18.5 & 10 & \\
\hline Gravel road & 30 & 3.8 & 10 & \\
\hline Scale road & 30 & 1.8 & 5 & \\
\hline Twist road & 10 & 1.6 & 5 & \\
\hline
\end{tabular}

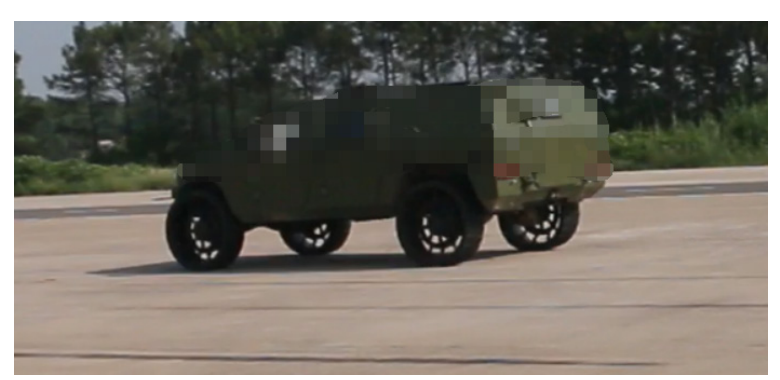

Fig. 21. ME-Wheel endurance road testing

The total vehicle mileage is about $1200 \mathrm{~km}$, and the ME-Wheel pin is broken. According to Table 6, it is calculated that the overall life of the ME-Wheel structure is $1200 \times 7.32=8784 \mathrm{~km}$.
A comparison of endurance road testing, theoretical calculations and finite element simulation, shows that the three results are close to each other. The deviation between the theoretical calculation and endurance road testing is $16.9 \%$, and the finite element calculation and endurance road testing deviation is only $12.07 \%$. Moreover, the validity of the simulation and theoretical calculation is verified. Through the analysis of above results, more reasonable deviation sources are:

1) The virtual endurance road is not complete; only five typical roads are selected and accounting for more than the road modelling and simulation.

2) The speed, weight and other parameters of test vehicle are slightly different from the simulation environment, which results in deviation during vehicle testing.

3) During the design of the ME-Wheel, the parameters used in ME-Wheel dynamic load calculation and finite-life design are conservative. Thus, the theoretical calculation and simulation results of ME-Wheel are smaller than the endurance road testing results to improve the safety factor.

\section{CONCLUSIONS}

1) The ME-Wheel finite element model is established, and its correctness is verified by bench test and tensile test. Based on the simulation results of ME-Wheel static strength, it ascertains that the weakest component is the pin, because the most stress is concentrated on it.

2) A life prediction model is suitable for the MEWheel, which is established by the finite-life design, and the theoretical life of the ME-Wheel can be predicted with relative precision. The results of theoretical calculation are compared with the durability simulation results and the endurance road testing results, the deviations are $5.49 \%$ and $16.9 \%$, respectively.

3) The virtual vehicle proving ground model is established, and the ME-Wheel life is predicted by the durability simulation. The comparison error between the simulation and endurance road tests is $12.07 \%$, which shows that the durabilityenhanced virtual proving ground model and motion simulation analysis can predict the MEWheel life relatively accurately. Furthermore, the analysis method applied in this paper can not only reduce the vehicle test time but also provide a reference for durability optimization in the future. 


\section{ACKNOWLEDGEMENTS}

Authors would like to thank the supported by the National Natural Science Foundation of China (No. 11672127), the Major Exploration Project of the General Armaments Department of China (No. NHA13002), the Fundamental Research Funds for the Central Universities (No. NP2016412), and Jiangsu Innovation Program for Graduate Education and the Fundamental Research Funds for the Central Universities (No. KYLX16_0330).

\section{REFERENCES}

[1] Kumar, A.S., Kumar, R.K. (2016). Force and moment characteristics of a rhombi tessellated non-pneumatic tire. Tire Science and Technology, vol. 44, no. 2, p. 130-148. DOI:10.2346/tire.16.440205.

[2] Cho, J.R., Lee, J.H., Jeong, K.M., Kim, K.W. (2012). Optimum design of run-flat tire insert rubber by genetic algorithm. Finite Elements in Analysis and Design, vol. 52, p. 60-70, D0l:10.1016/j.finel.2011.12.006.

[3] Jo, H., Lee, C., Kim, K., Kim, D. (2013). Vibration Characteristics of Non-pneumatic Tire with Honeycomb Spokes. Transactions of the Korean Society of Automotive Engineers, vol. 21, no. 4, p. 174-180. D0l:10.7467/ksae.2013.21.4.174.

[4] Ju, J., Kim, D.M., Kim, K. (2012). Flexible cellular solid spokes of a non-pneumatic tire. Composite Structures, vol. 94, no. 8 , p. 2285-2295, DOI:10.1016/j.compstruct.2011.12.022.

[5] Lee, Y.L., Pan, J., Hathaway, R.B., Barkey, M. (2005). Fatigue Testing and Analysis. Elsevier, New York.

[6] Liu, J., Wang, Y., Li, W. (2010). Simplified fatigue durability assessment for rear suspension structure. International Journal of Automotive Technology, vol. 11, no. 5, p. 659-664, D0l:10.1007/s12239-010-0078-1.

[7] Carpinteri, A., Spagnoli, A., Vantadori, S. (2009). Size effect in S-N curves: A fractal approach to finite-life fatigue strength. International Journal of Fatigue, vol. 31, no. 5, p. 927-933, D0l:10.1016/j.ijfatigue.2008.10.001.

[8] Gasmi, A., Joseph, P.F., Rhyne, T.B., Cron, S.M. (2012). Development of a two-dimensional model of a compliant non-pneumatic tire. International Journal of Solids and Structures, vol. 49, no. 13, p. 1723-1740, D0l:10.1016/j. ijsolstr.2012.03.007.

[9] Gasmi, A., Joseph, P.F. (2012). Contact solutions for a circular orthotropic beam accounting for transverse normal strain. International Journal of Engineering Science, vol. 55, p. 1-17, D0I:10.1016/j.ijengsci.2012.01.011.

[10] Kim K, Ju J. (2015). Mechanical metamaterials with 3D compliant porous structures. Composite Structures, vol. 132, p. 874-884, DOl:10.1016/j.compstruct.2015.06.060.

[11] Heo, H., Ju, J., Kim, D.M., Kim, H. (2014). A computational study of the flow around an isolated non-pneumatic tire. SAE International Journal of Passenger Cars: Mechanical Systems, vol. 7, no. 1, p. 405-412, D0l:10.4271/2014-01-9123.

[12] Kim, K., Ju, J., Kim, D. (2013). Static contact behaviors of a non-pneumatic tire with hexagonal lattice spokes. SAE
International Journal of Passenger Cars: Mechanical Systems, vol. 6, no. 3, p. 1518-1527, Dol:10.4271/2013-01-9117.

[13] Wang, C., Ayalew, B., Rhyne, T., Cron, S., Dailliez, B. (2015). Static analysis of a thick ring on a unilateral elastic foundation. International Journal of Mechanical Sciences, vol. 101-102, no. 429-436, DOI:10.1016/j.jjmecsci.2015.08.015.

[14] Wang, C., Ayalew, B., Rhyne, T., Cron, S., Dailliez, B. (2016). Forced in-plane vibration of a thick ring on a unilateral elastic foundation. Journal of Sound and Vibration, p. 380, p.279294, DOl:10.1016/j.jsv.2016.06.010.

[15] Zhao, Y.Q., Zang, L.G., Chen, Y.Q., Li, B., Wang, J. (2015). Non-pneumatic mechanical elastic wheel natural dynamic characteristics and influencing factors. Journal of Central South University, vol. 22, no. 5, p. 1707-1715, Dol:10.1007/ s11771-015-2689-1.

[16] Wang, W., Zhao, Y.Q., Wang, J., Zang, L.G. (2012). Structure analysis and ride comfort of vehicle on new mechanical elastic tire. Proceedings of the FISITA 2012 World Automotive Congress, Beijing, p. 199-209, Dol:10.1007/978-3-64233795-6_17.

[17] Wang, Q., Zhao, Y.Q., Du, X.B., Zhu, M.M., Fu, H.X. (2016). Equivalent stiffness and dynamic response of new mechanical elastic wheel. Journal of Vibroengineering, vol. 18, no. 1, p. 431-445.

[18] Zang, L.G., Zhao, Y.Q., Jiang, C., Li, B., Wang, W. (2015). Mechanical elastic wheel's radial stiffness characteristics and their influencing factors. Journal of Vibration and Shock, vol. 34, no. 8, p. 181-186. (in Chinese)

[19] Zang, L.G., Zhao, Y.Q., Li, B., Wang, Q., Fu, H.X. (2015). Static radical stiffness characteristics of non-pneumatic mechanical elastic wheel. Acta Armamentarii, vol. 36, no. 2, p. 355-362 (in Chinese)

[20] Li, B., Zhao, Y.Q., Zang, L.G. (2014). Closed-form solution of curved beam model of elastic mechanical wheel. Journal of Vibroengineering, vol. 16, no. 8, p. 3951-3962.

[21] Du, X.B., Zhao, Y.Q., Wang, Q., Fu, H.X. (2017). Numerical analysis of the dynamic interaction between a non-pneumatic mechanical elastic wheel and soil containing an obstacle. Proceedings of the Institution of Mechanical Engineers, Part D: Journal of Automobile Engineering, vol. 231, no. 6, p. 731742, D0I:10.1177/0954407016660946.

[22] Du, X.B., Zhao, Y.Q., Lin, F., Fu, H.X., Wang, Q. (2017). Numerical and experimental investigation on the camber performance of a non-pneumatic mechanical elastic wheel. Journal of the Brazilian Society of Mechanical Sciences and Engineering, vol. 39, no. 9, p. 3315-3327, D0l:10.1007/ s40430-016-0702-8.

[23] Akrache, R., Lu, J. (2011). Integrated design for fatigue life estimation of structures. Strojniški vestnik - Journal of Mechanical Engineering, vol. 57, no. 7-8p. 547-554, DOI:10.5545/sv-jme.2008.043.

[24] Sokolov, S.L. (2010). Prediction of the fatigue life of pneumatic tires. Journal of Machinery Manufacture and Reliability, vol. 39, no. 5, p. 459-465, D0l:10.3103/S1052618810050092.

[25] Sokolov, S.L. (2007). Calculation of the stress-strain state of pneumatic tires by the finite element method. Journal of Machinery Manufacture and Reliability, vol. 36, no. 1, p. 4549, DOI:10.3103/S1052618807010098. 
[26] Topac, M.M., Ercan, S., Kuralay, N.S. (2012). Fatigue life prediction of a heavy vehicle steel wheel under radial loads by using finite element analysis. Engineering Failure Analysis, vol. 20, no. 3p. 67-79, Dol:10.1016/j.engfailanal.2011.10.007.

[27] Rosa, U., Nagode, M., Fajdiga, M. (2007). Evaluating thermomechanically loaded components using a strain-life approach. Strojniški vestnik - Journal of Mechanical Engineering, vol. 53, no. 10, p. 605-620.

[28] Aghdam, N.J., Hassanifard, S., Ettefagh, M.M., Nanvayesavojblaghi, A. (2014). Investigating fatigue life effects on the vibration properties in friction stir spot welding using experimental and finite element modal analysis. Strojniski vestnik - Journal of Mechanical Engineering, vol. 60, no. 11, p. 735-741, D0I:10.5545/sv-jme.2013.1324.
[29] Saoudi, A., Bouazara, M. Marceau, D. (2011). Fatigue failure study of the lower suspension vehicle arm using a multiaxial criterion of the strain energy density. Strojniski vestnik Journal of Mechanical Engineering, vol. 57, no. 4, p. 345-356, DOl:10.5545/sv-jme.2009.074.

[30] Su, H. (2010). Automotive structural durability design using dynamic simulation and fatigue damage sensitivity techniques. SAE International Journal of Materials \& Manufacturing, vol. 3, no. 1, p. 1-12, D0l:10.4271/2010-01-0001.

[31] Park, D.W., Papagiannakis, A.T., Kim, I.T. (2014). Analysis of dynamic vehicle loads using vehicle pavement interaction model. KSCE Journal of Civil Engineering, vol. 18, no. 7, p. 2085-2092, D0I:10.1007/s12205-014-0602-3.

[32] Buch, A. (1988). Fatigue Strength Calculation. Trans Tech Publication, Zürich. 